Henning, Günter; Hoppe, Ulrich:

Grußwort zur 38. Jahrestagung der Deutschen Gesellschaft für Biomedizinische Technik im VDE (DGBMT)

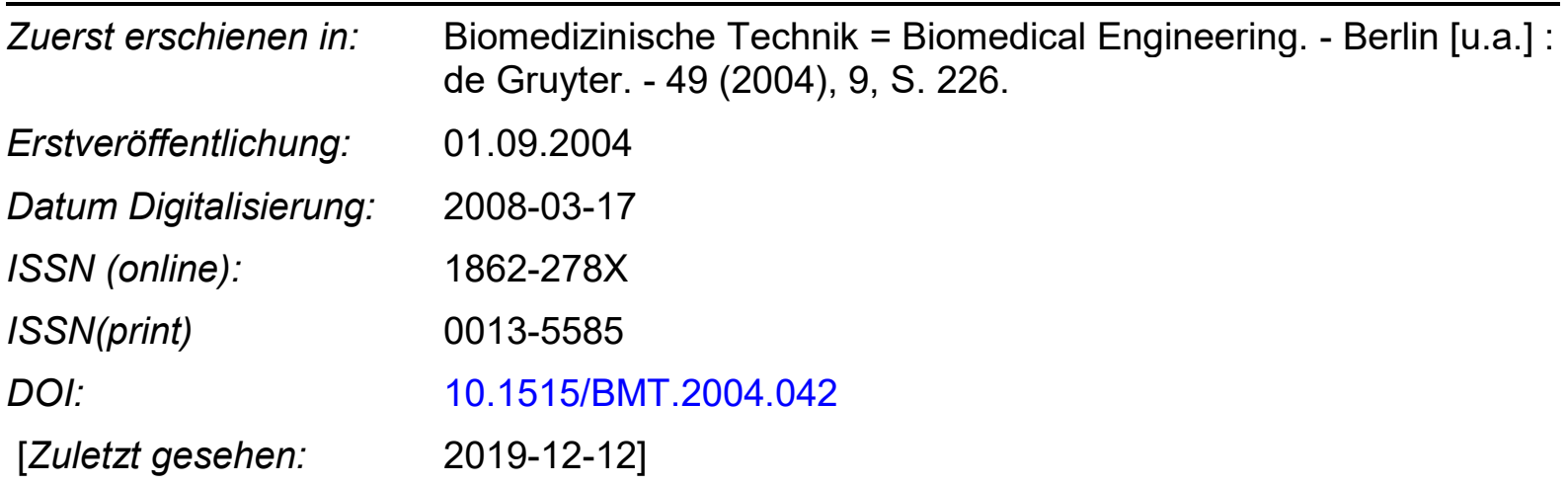

„Im Rahmen der hochschulweiten Open-Access-Strategie für die Zweitveröffentlichung identifiziert durch die Universitätsbibliothek IImenau."

"Within the academic Open Access Strategy identified for deposition by Ilmenau University Library."

„Dieser Beitrag ist mit Zustimmung des Rechteinhabers aufgrund einer (DFGgeförderten) Allianz- bzw. Nationallizenz frei zugänglich."

"This publication is with permission of the rights owner freely accessible due to an Alliance licence and a national licence (funded by the DFG, German DFG

Research Foundation) respectively." 


\title{
Grußwort zur 38. Jahrestagung der Deutschen Gesellschaft für Biomedizinische Technik im VDE (DGBMT)
}

\author{
21.-24. September 2004, IIImenau
}

Erstmals in ihrer nahezu 40jährigen Geschichte findet die Jahrestagung der Deutschen Gesellschaft für Biomedizinische Technik in IImenau statt. Für das Team des IImenauer BMT-Instituts - das im Jahre 2004 sein 50jähriges Gründungsjubiläum feiert - ist dies eine hohe Ehre und eine besondere Freude.

Die Einladung der Veranstalter zur 38. DGBMTJahrestagung hat eine außerordentlich hohe Resonanz gefunden: mit etwa 530 Beiträgen aus nahezu allen Anwendungsgebieten der Biomedizinischen Technik ist die Tagung wiederum deutlich gewachsen. Ein internationales Satellitensymposium "Cellular Engineering and Nanosensors" am 21. September 2004 fokussiert auf das junge, sich mit besonderer Dynamik entwickelnde Gebiet der medizinischen Biotechnologie. Der Studentenwettbewerb hat eine erfreulich hohe Zahl von Beiträgen angezogen. Das wissenschaftliche Programm der BMT 2004 wird erweitert durch drei BMBF-Workshops zu Schwerpunkten der geförderten BMT-Forschung. Ein Seminar zur neuen IEC-Empfehlung 60601-1 als Weiterbildungsange- bot wird das besondere Interesse der Medizintechnik-Unternehmen und Anwender finden.

Das Rahmenprogramm der Tagung bietet nach intensiver Arbeit Gelegenheit zu persönlichen Gesprächen, zur Anbahnung und Pflege von Kontakten und zur Entpannung in angenehmer Atmosphäre. Darüber hinaus lohnt sich ein Blick in das schöne Zentrum der etwa 750jährigen Stadt IImenau oder ein Ausflug in ihre schöne Umgebung bzw. in das nahe mittelalterliche Erfurt oder die Klassikerstadt Weimar.

Insgesamt hoffen wir, daß die 38. DGBMT-Tagung Ihnen viele neue Erkenntnisse vermittelt und anregende Diskussionen ermöglicht. Wir freuen uns sehr darauf, Sie in IImenau begrüßen zu dürfen!

Günter Henning

Ulrich Hoppe

Institut für Biomedizinische Technik und Informatik Technische Universität IImenau 